\title{
Understanding leadership in higher education as a tool for change in relation to gender
}

\author{
Andrew Power
}

\section{Traditional leadership theories}

A substantial volume of work has been written on the subject of leadership and many theories developed to explain it. Bennis and Nanus (1985) suggest that leadership is the most studied yet least understood topic of any in the social sciences. Many theories have been put forward including: 'great man' theory; trait and behaviourist theories; situational leadership; and contingency, transactional and transformational leadership theories. Feminist theories of leadership have brought much-needed and timely perspectives to the field (Rosener 1990; Klenke 1996; Loden 1985). In considering the emergence of female leaders, much is made of the benefits of diversity when constructing boards or leadership teams. Ironically, this view of leadership is strangely reminiscent of the discredited 'great man' theory of leadership. This theory held that the ability to be a great leader was something a person was born with rather than a set of skills that could be learned. The examples were frequently military leaders and thus built on the narrative of heroic leaders. An echo of this approach today can be seen in the way sporting heroes and their achievements are frequently discussed. This has sometimes led to a similarly reductive view of the different traits that women leaders may possess.

Two themes emerge with the first being a diminishing belief that leaders are born rather than made. Over time, it gradually became accepted that leadership skills could be studied, learned, or improved. The second development is the acceptance that leaders are not hermetically sealed or self-contained. Their leadership skills depend on outside forces such as the environment, the context or their relationship with their followers. Leadership is understood as a process of acknowledging, understanding and shaping these external factors.

An acknowledgement that leadership skills could be learned has led to a large and profitable training industry for managers, targeted mainly at the private sector. This was capitalised on in higher education through the creation and provision of Master's in Business Administration (MBA) (2018) programmes, the most frequently conferred master's degree in the United States (Byrne 2014). An even larger private leadership industry has emerged, for example The Leaders Institute or Dale Carnegie (www.leadersinstitute.com or www.ireland.dalecarnegie.com). 
The private sector led the way and dominated research and the development of leadership theory. Much of it has been popularised in management books or delivered in a practitioner-friendly form via company training sessions. Despite the fact that higher education has been providing leadership training to the business community there has been less impetus towards developing leadership development programmes within universities themselves. In more recent years, organisations such as AdvanceHE (www.lfhe.ac.uk/) in the UK have begun to address this with a number of specific programmes. Formed from the merger of related organisations in 2018, including the Leadership Foundation, one of the programmes which continues to be run in Higher Education Institutions, in the UK and Ireland, is the Aurora Leadership programme. The Aurora programme supports women and their institutions through a series of leadership workshops, mentoring and motivating interventions from senior female role models. In addition to the formal aspect of the programme the development of a network of early career women in higher education is a key benefit to participants.

The second theme of the research, that leaders must take greater control of their environment, is also easier for the leader in the private sector to conceptualise. For all the uncertainty of the market, a leader in the private sector has a clearer set of objectives and a smaller number of variables than a public sector leader or administrator. It is also likely that a private sector leader will have more control over the management of resources and more motivational levers at their disposal than in the public sector. In higher education, measures of success or failure are more complex and longer term. In addition, the connection between the funding of a department or the promotion of an individual academic are not tied in the same direct way to outputs. Simply setting targets, such as one that the gender or ethnic composition of the senior academic leadership reflects the student population or indeed the broader academia, is a positive but insufficient step. Targets have the advantage of being easier to introduce and they tend to meet less resistance from the dominant group who see them as less threatening. Targets are less threatening because they are difficult to enforce and slow to achieve change. More positive actions, such quotas, meet much more resistance as they are seen to undermine the dominant group. They are, however, a way to effect change more quickly.

A target-led approach can mean that the time taken to effect change can be longer and that changes are limited to organic or incremental change. Building leadership capacity, and more specifically increasing the number of senior female leaders within higher education, has been slow when left to the more passive approach of targets and aspirations. More positive approaches to achieving change are required and some are explored later. One approach to recruitment which has gained traction in the corporate technology sector and was imported from professional sports is the Rooney Rule (Fox 2015). Dan Rooney, former US ambassador to Ireland, 2009 to 2013, sought to address the fact that the majority of players in the US National Football League (NFL) were African American but almost none were head coaches. Rooney mandated that a minority candidate must be shortlisted for all interviews. In 2014 Microsoft and other IT companies have 
adopted the rule in relation to gender for appointments to their boards (Branson 2018). Approaches in Irish higher education have included requiring interview panels to be gender balanced and gender blind screening of CVs is becoming more common. Nevertheless, there is a need to develop the necessary knowledge and experience in institutions for making significant change.

O'Connor (2019) has questioned the gender competence of senior leaders in Irish HE and suggested that the lack of experience or knowledge amongst the predominately male leadership is one cause of this inertia. O'Connor draws attention to the recommendation of the Irish Higher Education Authority that in the appointment of all line mangers 'a requirement of appointment will be demonstrable experience of leadership in advancing gender equality' (HEA 2016, 47). The limited instances of positive action, whilst attracting some resistance and occasional controversy may be quicker to yield results and may seed change in the system. An example of this, in the Irish context, is the Senior Academic Leadership Initiative (SALI) (https://hea.ie/funding-calls/senior-academic-leadershipinitiative/) (see Chapter 12). This competitive process funded by the Irish Higher Education Authority provided for up to 45 (20 appointments in 2020) new and additional senior academic leadership posts to be awarded over three years from 2020 to accelerate gender balance at senior levels.

\section{The public sector and focus on implementation}

If leadership theories have been a preoccupation of researchers in the private sector then implementation theories hold a corresponding place in the public sector. Implementation refers to what happens between the establishment of a government intention and its consequent impact (O'Toole 1997). The public sector focus notes that policies announced at the top of the hierarchy have failed to be consistently implemented by those who are designated to deliver them.

In his review of the implementation literature, Matland $(1995,146)$ argued that it lacks a theoretical structure and despite a very large number of case studies, most writers fall into the 'top-down', or 'bottom-up', view of implementation. The topdown theorists, such as Pressman and Wildavsky (1984), were clear that policy sets the goals and implementation is about how those goals are satisfactorily and accurately executed. This resonates with ideas of a hierarchical leadership system with a 'great man' setting the rules. Bottom-up theorists such as Lipsky (1980) and his concept of a 'street-level bureaucrat' echo the transformative model of leadership where the followers, or subordinates, play a more important role in the process. The impact of external factors on the success or otherwise of administrative implementation were considered by Mazmanian and Sabatier (1983). They addressed factors such as public support, socio-economic conditions, support from sovereigns and the attitudes of constituency groups, analogous to the thinking demonstrated in situational or contingency leadership theories. However, the premise that if the system is designed correctly then the desired results will follow rarely refer to leadership as a significant factor in successful implementation. 
Their only reference to leadership is when they discuss the importance of the commitment of those engaged in implementation, whilst acknowledging that 'leadership skill remains a rather elusive concept' (Mazmanian and Sabatier 1983, 35).

The top-down hierarchical approach has shifted to a more inclusive, changedriven, transformational approach. This change in implementation theory increasingly sees the street-level bureaucrat, citizen and service user as an important part of the implementation process. This has relevance for alternatives to male leadership in universities, particularly when considering the question of whether women manage differently to men. The top-down approach emphasised a formal, structural way to lead where the power relationship was vertical and directional, which in turn played to the traditional hierarchical approach associated with male leadership. The shift to bottom-up leadership opened up the possibility of a more collaborative or participatory style of leadership, often linked to, or expected of, female leaders. A discussion of the emergence of alternative styles of leadership pioneered by female leaders is detailed by Drew (2008).

\section{Leadership in the public sector}

The task of leadership has become more complex in an organisational climate of shared power and openness. Public sector leaders face additional difficulties, relating to contextual complexity (Brunner 1997), first identified and described in relation to the difference in role between the leader of paid employees and those in a voluntary organisation:

issues on contextual complexity apply to mission, organisational and environmental culture, structure, types of problems, types of opportunities, levels of discretion and a host of other critically important areas.

(Van Wart 2003, 215)

Within the public sector, goals may be more complex, less measurable, or more susceptible to change. For example, the clarity of a private sector goal such as profit maximisation is likely to be absent and replaced by a more nebulous goal such as improved university ranking or more integrated research innovation. This contextual difference has contributed to the lack of crossover of some leadership theories, from the private to the public sector. Some believe that leadership does not, and should not, exist in the public sector, arising from the notion that administrative leadership in the public sector is driven entirely by political forces and bureaucracy (Van Wart 2003). Hence, leadership is the sole preserve of the political leadership and the role of public servants, at all levels, is to implement the will of government. In a review of leaders in the British public sector (Blackler 2006) chief executives in the NHS saw themselves as little more than conduits for central government policies and targets, rather than as reformers.

This is also evident in the Irish higher education sector, through initiatives to address change: linking research funding to gender balance; requiring senior 
appointees to have experience in advancing gender equality; the Senior Academic Leadership Initiative (SALI); and the requirement for HEIs to obtain Athena SWAN certification. All of these were driven by the Higher Education Authority (HEA), the Department of Education and Skills or by the Minister for Higher Education. None were led by the academic institutions who continue to see their role as implementors rather than leaders.

Irish academia is in a time of change, with debates about the funding mechanism for higher education, the changing role of providers, the merging of some institutions and the general shifting landscape of provision with gender equality sought in leadership roles. There is opportunity in times of flux to make radical change but the signals are mixed. On the one hand initiatives on research funding, as developed by Doona in Chapter 12, is positive, as is the SALI initiative. On the other hand, recent opportunities to appoint the first woman to the position of president of an Irish University or Technological University has not materialised. The growing awareness of gender imbalance as an issue and the adoption of the Athena SWAN Charter is to be welcomed, but until institutions move from data collection and monitoring to the more direct approach of promoting more women as leaders, progress will remain incremental.

Van Wart $(2003,221)$ offers a range of definitions of leadership specific to the public sector, ranging from bureaucratic 'the process of providing the results required by authorized processes in an efficient, effective, and legal manner'; motivational 'developing and supporting followers'; political 'aligning the organization with its environment', public service 'dedicated to the common good'; or a combination of all of these. This language is different from the language of private sector leadership theory. There is no discussion of the transactional nature of the relationship between leader and follower nor is there a sense of the transformational nature of the leader as an agent for change. This is important since the gendered nature of leadership is often characterised by a distinction between male (transactional, direct, task orientated) and female (transformational, participative, people orientated) (Rosener 1990).

Leadership throughout the public sector has focused less on change and more on doing the same tasks more efficiently, effectively or accountably. In Ireland, for example, the effectiveness of the public sector is regularly reported on by the comptroller and auditor general, whose annual reports provide an insight into the efficiencies of the organs of the state. Callahan (2007) expressed concern that the accountability burden is undermining performance since more time is now spent on the administrative burden of documenting rather than on improving performance. Horan (2007) commented that over-reporting is an increasing feature and obligation of senior managers in the public sector. In the specific case of higher education this approach has found expression in the importation from the broader public sector of much of the ideas of New Public Management (Tolofari 2005; Broucker and De Wit 2015). In addition to increasing metrics for expected activities such as research and publications the language of: performance; service delivery; management by objectives; and management by incentive, are now part 
of the landscape of performance metrics and agreements between academic institutions and the state.

While recognising some of the advantages which result from New Public Management, two problems arise from this transformation in thinking. First, changes which saw recipients of public services as consumers rather than citizens resulted in some inappropriate behaviours as systems designed for profit maximisation were applied to situations requiring service optimisation. In the case of higher education it is problematic to think of students as customers and yet issues such as recruitment, retention, progression and, of course, student fees, feed into this thinking. Second, while some management theories and techniques were imported from business schools and the private sector, theories of leadership which were advancing in the private sector were largely ignored by the public sector. An obvious example is the impracticality of applying a sales culture of targets, bonuses and so on, when higher education does not see itself in the business of sales. Another change is the growing recognition of the diversity of the customer base. Businesses may have slowly begun to see that if their leadership team better reflected the diversity of their customers, they might gain a better insight into how best to meet their needs. This could be seen as 'good for business'. In academia, the same link between leadership insight to the growing diversity of the student population has not been recognised nor has it been applied to systematic considerations of gender.

The current emphasis on control and measurement runs contrary to the idea of leadership, which is about movement and change. Despite the contextual differences in the public sector, effective leadership is essential. Mobilising public organisations to accomplish their mandated purpose is constrained by ministerial ability to provide leadership for multiple agencies and functions for which they are responsible. Government may provide the public servant or agency with vague or conflicting goals and, inevitably, with insufficient resources. Leadership is also important to prevent capture by external interest groups of the public agenda for their own purpose. Finally, leadership in the public sector is important because the citizens whose will is served by the public servant may not have the knowledge or information to achieve the solution to their issue (Behn 1998a, 1998b).

\section{Women and leadership}

Despite the many advances in leadership theory there is still a strongly held idea of 'heroic individualistic' leadership. This means that successful female leaders may be compared unfavourably with their male counterparts or, as 'unicorns', rare, unusual and exceptional individuals. Lack of female leaders in the workplace has less to do with the nature or ability of women and everything to do with the gendered nature of the workplace. Women face a range of gendered assumptions and stereotypes about their fitness for leadership, which are then translated into discriminatory norms and organisational practices in areas such as recruitment and promotion (Marshall 1984). Examples of the consequences of these gendered 
assumptions are noted in Chapters 3, 4 and 7, which refer to gendered recruitment, career progression and the gender pay gap respectively.

There is a lack of female leadership at the highest levels of academia worldwide (Morley 2013). In the EU, only 15 per cent of rectors or vice-chancellors are women (European University Association 2016). Manfredi (2017) argues that universities need to tackle the invisible barriers which prevent women from progressing into senior roles, namely: the gendered construction of leadership and the impact of unconscious bias (see Chapter 9) which results in women being constantly judged less favourably than men; and the cumulative disadvantage they face throughout their careers.

The gender construction of leadership refers back to the traditional understanding of leadership. A more evolved understanding of leadership styles appropriate to the business or academic environment brings with it a demand for more diverse skills. Drew (2008) discusses how feminine leadership brings an added dimension rather than being a replacement of a more traditional approach. The adoption of more open, collaborative styles of leadership, with greater emphasis on consensus and equality, not only give opportunities to women leaders to exercise their skills but also allow male leaders to learn from and develop their own style of leadership. Examples of female leaders who have achieved positions of leadership in universities are rare, but it is possible to detect a distinctive voice. Professor Richardson, the first female vice-chancellor of the University of Oxford called for the education of future leaders who can 'think critically' and 'act ethically' in order to better deal with issues like financial crises. She also acknowledged the importance of diversity in universities stating, 'in an increasingly complex world, the best may not be those who look and sound like ourselves' (BBC News 2016). The first female president of Harvard challenged those women who achieve success in leadership positions to maintain this distinctive voice: 'sustain our commitment to fairness and justice for women here and around the world' (Faust 2014).

Difficulty in achieving leadership responsibilities in universities is often compounded by a gendered division of labour in academia, with women more likely to have greater teaching, administrative and pastoral responsibilities. These tend to be less valued than research (Manfredi 2017). This topic is also the subject of Chapter 4 (Kinahan et al). Positive action is one way in which change can be accelerated. In Ireland, state funding of academia is now linked to the proportion of women at full professorial level and the setting of a gender target of 40 per cent by 2024 (HEA 2016). Instigating gender change in an organisation has often been portrayed as the responsibility of the aspiring female leader, thus absolving the organisation of some of the responsibility. Branson (2018) is critical of the long list of books authored by successful female leaders offering self-help, since they fail to address organisational change, for example Sandberg (2013). Burkinshaw and White (2017) argue that while interventions aimed at helping women break through the glass ceiling are common, the gendered power relations in universities have not changed. Their study indicated that while older, and more senior, female leaders had learnt to fit in and accommodate the prevailing culture, 
younger women in the leadership pipeline questioned if the price of accommodating the organisational culture to progress their careers was worthwhile.

Manfredi (2017) recognised that a one-off focus on positive action may not be enough to tackle structural and systemic gender issues across institutions. Developing a framework could enable institutions to learn from the application of positive action, to reflect on their practices and on how merit is constructed and assessed. This involves setting aspirational targets to increase gender diversity in senior roles across an institution as well as adopting positive action in recruitment and promotion. It also calls for the recognition of issues such as unconscious bias (Chapter 9) or organisational blind spots. This virtuous circle leads back to the setting of new targets to close the gender gap in leadership roles.

Women's leadership often involves working within, around and underneath institutional, cultural and societal contexts. Blackmore and Sachs (2007) discuss how this leadership style, born of a hostile environment, may well involve a process of both performing and reforming, of simultaneously working within existing institutional arrangements and structures, while also arguing for new ways of organising and modelling new forms of leading. Their view of leadership is more about articulating and sharing ideas and understanding when to take action. They suggest an almost subversive approach to working outside, against and within the system. In addition to mentoring and communication they emphasise the importance of six elements identified by Day (2004) for successful leadership: achievement, care, collaboration, commitment, trust and inclusivity. Many of these elements should form part of a positive mentoring process. Mentoring, and the more active approach of sponsorship, could be part of the informal, individual driven, and the formal, organisational driven, approaches to building leadership capacity. Mentoring schemes driven by a university, such as in the Aurora Women's Leadership programme, provide a network of mentors and mentees. Female leaders demonstrate a sensitivity to the context of interpersonal relations, habits and customs that determine the meanings and associated expectations of formal rules. Blackmore and Sachs (2007) note that this social capital often came from outside rather than within their organisations (unions, social movements, professional organisations, community networks).

\section{Leaders and followers}

Leadership, strategy and change are different ways of looking at the same phenomenon. To lead is to move or change and strategy involves planning for such change. Leadership can reside in the follower and not just in the leader. In this way, leadership can be seen as a series of leadership acts rather than as a distinct role. Looking at leadership as a process between a series of actors in which all participants play a vital role, where leadership skills are nurtured and developed, has a resonance in the public sector environment, since teams are less likely to change quickly and developing teams is more productive than seeking to replace members. Problems are often long-term and systemic rather than resolvable by 
short-term actions. In academia, teams of colleagues, based either on departmental and faculty structures, or on research interests, are likely to be stable over a number of years. This environment would benefit most from a style of shared leadership where relationships develop over time. O'Connor et al (2019) explored the specific power relationships in research environments in which power is often covertly exercised by those with control over strategic direction and resources and what they describe as 'stealth power' is frequently male dominated. This is clearly unproductive and undermining of trust. Seeing leadership in higher education as a long-term relationship between individuals who bring their diverse skills and knowledge to a problem requires more conscious effort than a top-down direction but is considerably more productive.

Kramer (1995) argues that leadership is a form of relationship not dependent on the specific traits of an individual, building on the ideas of the transactional model of leadership. There is a relationship or transaction between follower and leader which is dynamic and changeable. Transformational leadership is based on the idea that the essential function of leadership is to produce adaptive or useful change (Kotter 1990; Van Wart 2003) and the leadership style adapts to the needs of the task or situation. The fusion of transactional and transformational leadership has emerged from studies which build a unified theory of leadership containing both relationship-building and change management elements of leadership. For example, Hooper and Potter (1997) talk about 'transcendent leaders' who can engage emotionally with their followers and transcend change.

This concept can be traced back to Parker Follett (1868-1933) who looked at lateral relationships across organisations and envisaged what would now be recognised as matrix-style organisations. This move away from a traditional hierarchical organisation focused on the informal relations within an organisation and a more dynamic set of power relations (Graham 1995). Parker Follett developed the concept of 'power with' rather than 'power over' and coined the phrase 'winwin approach'. This approach to problem solving or conflict resolution within an organisation embraced a range of views and can be seen as a precursor to understanding that diversity provides a mechanism for a broader understanding of issues. Discussing Parker Follett's work, Rusch (1991) attributed concepts such as transformational leadership, the interrelationship of leadership and followership, and the power of collective goals of leaders and followers to her lectures of 1927. This work expanded on the concept of hierarchical organisations and opened the possibility of more collaborative matrix style organisations, where the collaborative, networking and participative skills which Rosener (1990) associated with female leaders, were more valued. In higher education there are examples of this where staff may have a direct departmental or faculty manager but need to build similar productive relationships with the chairs of committees or research groups.

Seeing leadership as a relationship necessitates considering the role of the follower, involving a two-way process requiring effort, energy and a belief in common purpose, by both parties: 
Corporations and government agencies everywhere have executives who imagine that their place on the organization chart has given them a body of followers, and of course it has not. They have been given subordinates. Whether the subordinates become followers depends on whether the executives act like leaders.

(Gardner 1990, 3)

Followers are as intrinsic a part of the leadership process as leaders, where the role of leader might move between individuals. Rost (1991) argued that a new view of followers is necessary, in which a follower has an active role and must make a choice to perform that role. It is also possible that followers can be transformed into leaders and leaders into followers. This rotation of leadership, or the building of leadership skills within all members of the team, is well suited to an academic environment where organisational change is often slow and opportunities for formal progression limited. The opportunity to build up the skills of leadership in a matrix environment rather than imposing a constant hierarchy, provides the opportunity to maximise the skills of all.

Distributed leadership (Gronn 2002) offers some guidance, relying as it does on 'concertive action' where people pool ideas and expertise, so producing services and leadership energy that is greater than the sum of their individual capacities. Distributed leadership can take the form of spontaneous collaboration on tasks. Leadership is evident in the interaction and relationships in which people with different skills, expertise and from different organisational levels coalesce to pool expertise and agree conduct for the duration of the task. It also exists in shared roles which emerge between two or more people, involving close joint working 'within an implicit framework of understanding' and emergent 'intuitive understandings'. Finally, it can exist in the institutionalisation of structures, working together for example via committees. The advantages of distributed leadership amount to 'an overall widening of the net of intelligence and organisational resourcefulness' (Gronn 2002, 37). The concepts of shared and distributed leadership are also discussed by Brookes (2007). In addition to empowering the traditional 'follower' this concept requires a considerable change to the traditional 'leader' who may see the process as undermining or threatening. However, for those open to seeing the first role of leadership as being to create new leaders, the opportunities for men and women to learn and grow in their leadership skills provides a pool of potential leaders for the organisation as a whole.

Peck and P. 6 state that 'the governance and management of many public services have been increasingly subject to tight surveillance, detailed central rulemaking about how decisions should be made in an attempt to eliminate uncertainty' $(2006,21)$. They argue that this is misguided and that implementation in the public service is a creative process of change and adaptation. The aversion to risk in the public sector may have its roots in a conservatism or caution in dealing with public funds, where there is little or no perceived reward for instigating innovative change. The changeable nature of public policy, resulting from regular changes in 
government, may also play a part, or that the problems facing the public service are seen as just too complex (Van Bueren et al 2003). Dunoon (2002) suggests that management is about ensuring stability and continuity and that leadership is concerned with change and transformation. The emphasis on management rather than leadership in the public sector may derive from the fact that a management approach can produce tangible, measurable results. Leadership involves more risk and less certain outcomes. Academia has been willing to take on the many initiatives which have been initiated centrally or politically. It is now time for universities and institutes to demonstrate their ability to move beyond the implementation of reports and to do what centres of learning do best, innovate, change and grow. Academic institutions value their independence and autonomy; with that comes the responsibility to show their capacity for leadership. Comparing the approach to leadership in the public sector against the approach of the private sector, the issue comes down to adaptability, responsiveness and risk. Changes in thinking about leadership in the public sector have been slow whereas the private sector continues to be more agile in its ability to respond to changing circumstances. Some of the limitations to adaptability and responsiveness in the public sector are structural, such as contracts of employment, while others are as a result of the nature of the services supplied. It can be argued that some aspects of the public service merit risk aversion but in the case of higher education change and innovation is clearly needed.

\section{Conclusion}

The study of leadership in the public sector and higher education has been limited in the past, relative to the private sector. This may have been due in part to the different nature of the environment, less appetite for risk and a relative lack of autonomy. This is changing and one of the motivations is the recognition that the gender imbalance in senior positions in higher education is neither acceptable nor sustainable. This chapter suggests that the slow pace of change achieved by past attempts at developmental initiatives and goal setting should be augmented by a more positive approach to change. A greater appetite for risk and reward, more common in the private sector, could challenge the status quo and achieve real change. Building leadership capacity and skills throughout the academic staff, linking resources to a gender balanced leadership teams, seeding leadership posts in areas of specific gender imbalance, are all positive moves to achieve a community of academic leaders more reflective of the student population they seek to inspire.

\section{References}

BBC News (2016) New Oxford vice-chancellor urges 'open-minded'students. Available at: www.bbc.com/news/uk-england-oxfordshire-35290156

Behn, R. (1998a) The new public management paradigm and the search for democratic accountability, International Public Management Journal, 1 (2), 131-164. 
Behn, R. (1998b) What right do public managers have to lead? Public Administration Review, 58 (3), 209-224.

Bennis, W. and Nanus, B. (1985) Leaders: The strategies for taking charge, Harper \& Row, New York.

Blackler, F. (2006) Chief executives and the modernisation of the English national health service, Leadership, 2 (1), 5-30.

Blackmore, J. and Sachs, J. (2007) Performing and reforming leaders: Gender, educational restructuring, and organizational change, State University of New York (SUNY) Press, Albany.

Branson, D. (2018) The future of tech is female: How to achieve gender diversity, New York University Press, New York.

Brookes, S. (2007) Are public leaders up to standard? CSL Leadership Review, 1 (4), 211224, Centre for Studies in Leadership, University of Guelph, ON.

Broucker, B. and De Wit, K. (2015) New public management in higher education, in J. Huisman, H. de Boer, D. Dill and M. Souto-Otero (eds), The Palgrave international handbook of higher education policy and governance, Palgrave Macmillan, London.

Brunner, R. (1997) Teaching the policy sciences: Reflections on a graduate seminar, Policy Sciences, 39 (2), 217-231.

Burkinshaw, P. and White, K. (2017) Fixing the women or fixing universities: Women in HE leadership, Administrative Science, 7 (30), 1-14.

Byrne, J. (2014) Why the MBA is now the most popular masters, Poets and Quants, 26 May. Available at: http://poetsandquants.com/2014/05/26/why-the-mba-is-now-themost-popular-masters/

Callahan, K. (2007) Elements of effective governance: Measurement, accountability and participation, CRC Press, Boca Raton.

Day, C. (2004) The passion of successful leadership, School Leadership and Management, 24 (4), 425-438.

Drew, E. (2008) Leadership for business excellence: The gender perspective, in K. Foley and P. Hermel (eds), The theories and practices of organization excellence: New perspectives, SAI Global, Sydney, 269-293.

Dunoon, D. (2002) Rethinking leadership for the public sector, Australian Journal of Public Administration, 61 (3), 3-18.

European University Association (2016) More women become university leaders-equality still far away. Available at: https://eua.eu/news/41:more-women-become-universityleaders-equality-still-far-away.html

Faust, D. G. (2014) History of presidency: 'It can be otherwise', Harvard University Press. Available at: www.harvard.edu/president/speech/2014/it-can-be-otherwise

Fox, A. (2015) How the Rooney rule succeeds and where it falls short, ESPN Magazine. Available at: https://abc7ny.com/sports/how-the-rooney-rule-succeeds-and-where-itfalls-short/730588/

Gardner, J. (1990) On leadership, The Free Press, New York.

Graham, P. (1995) Mary Parker Follett-prophet of management: A celebration of writings from the 1920s, Harvard Business School Press, Boston, MA.

Gronn, P. (2002) Distributed leadership, in K. Leithwood, P. Hallinger, K. Seashore Louis, G. Furman Brown, P. Gronn, W. Mulford and K. Riley (eds), Second international handbook of educational leadership and administration, Kluwer, Dordrecht.

HEA (2016) National review of gender inequality in Irish higher education institutions, Higher Education Authority, Dublin. 
Hooper, A. and Potter, J. (1997) The business of leadership, Ashgate, Aldershot.

Horan, A. (2007) Governance and performance: Some dilemmas, Administration, 55 (1), 195-224.

Klenke, K. (1996) Women in leadership: A contextual perspective, Springer, New York.

Kotter, J. (1990) A force for change: How leadership differs from management, Free Press, New York.

Kramer, R. (1995) Carl Rogers meets Otto Rank: The discovery of relationship, in T. Pauchant (ed), In search of meaning: Managing for the health of our organizations, our communities, and the natural world, Jossey-Bass, San Francisco, 197-223.

Lipsky, M. (1980) Street-level bureaucracy: Dilemmas of the individual in public services, Russell Sage Foundation, New York.

Loden, M. (1985) Feminine leadership or how to succeed in business without being one of the boys, Time Books, New York.

Manfredi, S. (2017) Increasing gender diversity in senior roles in HE: Who is afraid of positive action?, Administrative Sciences, 7 (2), 1-14.

Marshall, J. (1984) Women managers: Travellers in a male world, Wiley, Chichester.

Masters Programs Guide (2018) Available at: www.mastersprogramsguide.com/rankings/ popular-masters-degrees/

Matland, R. (1995) Synthesizing the implementation literature: The ambiguity-conflict model of policy implementation, Journal of Public Administration Research \& Theory, 5 (2), 145-175.

Mazmanian, D. and Sabatier, P. (1983) Implementation and public policy, University Press of America, Lanham, MD.

Morley, L. (2013) Women and higher education leadership: Absences and aspirations, Leadership Foundation for Higher Education, London.

O'Connor, P. (2019) Creating gendered change in Irish higher education: Is managerial leadership up to the task? Irish Educational Studies, doi:10.1080/03323315.2019. 1697951

O’Connor, P., Martin, P., Carvalho, T., O’Hagan, C., Veronesi, L., Mich, O., Saglamer, G., Tan, M. and Caglayan, H. (2019) Leadership practices by senior position holders in higher educational research institutes: Stealth power in action, Leadership, 15 (6), 722 743, doi.org/10.1177/1742715019853200

O'Toole, L. (1997) Implementing public innovations in network settings, Administration \& Society, 29 (2), 145-174.

Peck, E. and P. 6 (2006) Beyond delivery: Policy implementation as sense-making and settlement, Palgrave Macmillan, Basingstoke.

Pressman, J. and Wildavsky, A. (1984) Implementation, University of California Press, Berkeley.

Rosener, J. (1990) Ways women lead, Harvard Business Review, 68, November-December, $119-125$.

Rost, J. (1991) Leadership for the twenty-first century, Praeger, Westport.

Rusch, E. (1991) The social construction of leadership: From theory to praxis, paper presented at the Annual conference on research on women and education, 7-10 November, San Jose.

Sandberg, S. (2013) Lean in: Women, work and the will to lead, Knopf, New York.

Tolofari, S. (2005) New public management and education, policy futures, Education, 3 (1), 75-89. 
Van Bueren, E., Klijn, E. and Koppenjan, J. (2003) Dealing with wicked problems in networks: Analyzing an environmental debate from a network perspective, Journal of Public Administration Research and Theory, 13 (2), 193-212.

Van Wart, M. (2003) Public-sector leadership theory: An assessment, Public Administration Review, 63 (2), 214-228. 